\title{
Better transplant outcome with pre-transplant marrow response after hypomethylating treatment in higher-risk MDS with excess blasts
}

\author{
Seung-Ah Yahng ${ }^{1}$, Myungshin Kim²,3, Tae-Min Kim ${ }^{4}$, Young-Woo Jeon ${ }^{5}$, Jae-Ho \\ Yoon ${ }^{5}$, Seung-Hwan Shin ${ }^{6}$, Sung-Eun Lee ${ }^{5}$, Ki-Seong Eom ${ }^{3,5}$, Seok Lee ${ }^{3,5}$, Chang- \\ Ki Min ${ }^{3,5}$, Hee-Je Kim ${ }^{3,5}$, Dong-Wook Kim ${ }^{3,5}$, Jong-Wook Lee ${ }^{5}$, Woo-Sung Min ${ }^{5}$ and \\ Yoo-Jin Kim ${ }^{3,5}$ \\ ${ }^{1}$ Incheon St. Mary's Hospital, College of Medicine, The Catholic University of Korea, Incheon, Korea \\ 2 Department of Laboratory Medicine, Seoul St. Mary's Hospital, College of Medicine, The Catholic University of Korea, Seoul, \\ Korea \\ ${ }^{3}$ Leukemia Research Institute, College of Medicine, The Catholic University of Korea, Seoul, Korea \\ ${ }^{4}$ Department of Medical Informatics, College of Medicine, The Catholic University of Korea, Seoul, Korea \\ ${ }^{5}$ Catholic Blood and Marrow Transplantation Center, Seoul St. Mary's Hospital, College of Medicine, The Catholic University \\ of Korea, Seoul, Korea \\ ${ }^{6}$ Yeoido St. Mary's Hospital, College of Medicine, The Catholic University of Korea, Seoul, Korea \\ Correspondence to: Yoo-Jin Kim, email: yoojink@catholic.ac.kr \\ Keywords: higher-risk myelodysplastic syndrome, marrow response, hypomethylating treatment, allogeneic hematopoietic stem \\ cell transplantation \\ Received: February 09, $2016 \quad$ Accepted: October 01, $2016 \quad$ Published: October 06, 2016
}

\section{ABSTRACT}

Hypomethylating treatment (HMT) has been suggested as a feasible bridge to hematopoietic stem cell transplantation (HSCT), but controversies exist around influences of HMT response on transplant outcomes. To assess the safety and influences of pre-transplant HMT focusing on debulking effects and transplant outcomes, we retrospectively analyzed consecutive HSCT-eligible patients who received HMT for higher-risk MDS with excess blasts. Of all 98 patients, 11 patients failed to proceed to HSCT and HMT-related mortality occurred in 8 patients. When excluding 9 patients who refused HSCT, 87\% of scheduled HSCT (77 of 89) was performed after a median of 3 cycles (range, 1-8) of HMT. The 4-year overall survival after HMT $(n=98)$ and HSCT $(n=77)$ was $44.0 \%$ and $53.6 \%$, respectively. Transplant outcomes were significantly different by the final response at HSCT; marrow response group (complete remission, marrow complete remission with or without hematologic improvement) showed significantly better 4-year disease-free survival compared to no marrow response group ( $n=36,87.3 \%$ vs. $n=41,10.7 \%, P<0.001$ ). This difference between the groups was also evident in overall survival $(90.9 \%$ vs. $8.6 \%$, $P<0.001)$ and cumulative incidences of relapse $(6.5 \%$ vs. $45.4 \%, P<0.001)$ and treatment-related mortality $(6.2 \%$ vs. $43.9 \%, P<0.001)$. These observations indicate that pre-transplant HMT is a feasible bridging treatment in patients with excess blasts regarding high success rate of proceeding to transplantation and good survival rate. Marrow response at HSCT regardless of concomitant hematological improvement is an independent predictor of better survival, suggesting that immediate HSCT rather than continuing HMT should be performed once marrow response is achieved. 


\section{INTRODUCTION}

Allogeneic hematopoietic stem-cell transplantation (HSCT) remains the only curative strategy to treat patients with myelodysplastic syndromes (MDS), and the role of bridging therapy using intensive chemotherapy or hypomethylating agents followed by HSCT in higherrisk MDS has been suggested [1]. Advances in the uses of alternative donors and reduced intensity conditioning regimens have extended the use of allogeneic HSCT to a wider number of patients, while high-resolution HLA typing and better supportive care facilitated minimizing treatment-related toxicities in older and less fit patients [2, $3]$.

However, the efficacy of HSCT in higher-risk MDS remains unsatisfactory, compared to that in lowerrisk MDS, due to the high rates of relapse (30-40\%) and treatment-related mortality (TRM; 30-50\%), leading to worse long-term disease-free survival (DFS; $<30 \%$ for higher-risk MDS) [4-6]. To achieve successful pre-transplant disease control, as well as reduce posttransplant relapse, pre-transplant intensive chemotherapy has been tried for patients with higher-risk MDS with excess blasts who are particularly at risk of brisk disease progression (DP) and transformation to acute myeloid leukemia (AML) $[6,7]$.

Feasibility of pre-transplant hypomethylating treatment (HMT) has been suggested in several previous reports [8-11]. HMT is currently a standard therapy for aged or debilitated patients with higher-risk MDS by its favorable toxicity profile $[1,12]$ and substantial response rate even in patients with poor cytogenetics [13-14]. In our previous report, the positive effect of HMT response on post-transplant survival was mostly due to marrow response in patients with higher-risk MDS [11], suggesting that the influences of HMT response might be associated with debulking effects of HMT. Currently, there has been little research on the use of HMT for "debulking strategy" focusing on higher-risk MDS with excess marrow blasts at HMT; thus, the issue as to whether HMT could be an alternative to induction chemotherapy in the setting remains to be clarified.

Given the above, this retrospective study was designed to assess the role of pre-HSCT HMT by analyzing treatment toxicities, rates of proceeding to HSCT, and influences of response type (especially marrow response) on transplant outcomes. To minimize selection bias, we included all consecutive HSCT-eligible patients who received HMT for higher-risk MDS with excess blasts.

\section{RESULTS}

\section{Baseline characteristics at pre-transplant HMT}

Ninety-eight patients (61 men and 37 women) with higher-risk MDS [15] and excess marrow blasts eligible for HSCT had received azacitidine $(n=66)$ or decitabine $(n=32)$. HMT was initiated from a median of 20 days (range, 1-180 days) after the diagnosis of higher-risk MDS. The median age of patients was 53 years (range, $18-65$ years). The cytogenetic risk was good in 44 cases $(45 \%)$, intermediate in 29 cases $(30 \%)$ and poor in 25 cases $(25 \%)$, and the median percentage of bone marrow blast at HMT was 13 (range, 6-19).

\section{Response and disease course after pre-transplant HMT}

Of all 98 study patients, 59 patients (60\%) showed a treatment response after a median of 2 cycles (range, 1-9 cycles) of HMT, and their best responses were complete remission (CR, $n=12)$, marrow $\mathrm{CR}$ with hematologic improvement $(\mathrm{mCR}+\mathrm{HI}, n=12), \mathrm{mCR}$ without $\mathrm{HI}$ (mCR-HI, $n=26$ ), and stable disease with $\mathrm{HI}(\mathrm{SD}+\mathrm{HI}$, $n=9$; Figure 1A). Eleven (11\%) patients became HSCTineligible (HSCT failure), and HMT-related mortality occurred in 8 of 98 patients $(8.2 \%)$. Nine $(9 \%)$ patients refused HSCT, while 1 patient was in its preparation at our data cut-off point. When excluding 9 patients who refused HSCT, $87 \%$ of scheduled HSCT (77 of 89 patients) was performed after a median of 3 cycles (range, 1-8) of HMT. Responses at the time of HSCT revealed that 44 patients $(57 \%)$ continuously maintained their best responses to HMT (continued response), 27 patients (35\%) never responded to HMT (primary failure; SD$\mathrm{HI}, n=17$; primary DP, $n=10)$, and 6 patients ( $8 \%)$ lost their best responses (secondary failure; relapse from CR, $n=1$; relapse from mCR-HI, $n=5$ ). AML-like induction chemotherapy was administered in 9 of the 11 patients with AML transformation (primary DP to AML, $n=10$; relapse in AML from mCR-HI, $n=1)$. Further details are illustrated in Figure 1A.

The median overall survival (OS) for all patients from the initiation of HMT was 39.3 months $(95 \%$ confidence interval [CI]: 23.9-54.6 months; Figure 1B), whereas the OS for the patients who received a transplant did not reach the median (Figure 1C). The median OS for patients in HSCT failure and those in HSCT refusal were 4.3 months (95\% CI: 0.6-8.1 months; Figure 1D) and 15.8 months (95\% CI: 12.4-19.1 months; Figure 1E), respectively. 


\section{Outcomes of transplantation following pre- transplant HMT}

Seventy-five of the 77 transplant patients (97.4\%) achieved primary engraftment, with median times to neutrophil and platelet engraftment of 12 days (range: 10-23 days) and 16 days (range: 9-51 days), respectively, while 2 patients died before neutrophil recovery could occur 22 and 24 days after graft infusion. The cumulative incidence of 100-day grade II-IV acute graft-versus-host disease (GVHD) was $29.9 \% \pm 5.3 \%$, and that of 2-year chronic GVHD among the evaluable patients $(n=73)$ was $48.1 \% \pm 5.9 \%$. After a median follow-up of 41.2 months (95\% CI: 25.3-57.6 months) among the survivors, 47 patients are currently alive in remission $(n=46)$ or in relapse $(n=1)$, and 30 patients have died due to relapse $(n=15)$ or TRM $(n=15)$. The causes of TRM were extensive chronic GVHD $(n=4)$, grade IV acute GVHD $(\mathrm{n}=4)$, and infection $(n=7)$. The 4-year probabilities of DFS and OS after HSCT were $53.6 \% \pm 6.5 \%$ and $53.8 \%$ $\pm 6.6 \%$, respectively, and the 4-year cumulative incidence of relapse (CIR) and TRM (CITRM) were $23.9 \% \pm 5.4 \%$ and $22.5 \% \pm 5.4 \%$, respectively.

\section{Effect of HMT response at HSCT on transplantation outcomes}

The 4-year post-transplant DFS according to the best response (Figure 2A) or the final response at HSCT (Figure 2B) after HMT was different. Based on the poor median DFS of patients with secondary failure (9.3 months), the final response at HSCT was chosen to further evaluate the effect of HMT response on transplantation outcomes. Observing significantly better DFS rates in patients with CR $(100 \%), \mathrm{mCR}+\mathrm{HI}(80.8 \%)$, and $\mathrm{mCR}-\mathrm{HI}(85.9 \%)$ at HSCT, the response at HSCT was dichotomized into

A
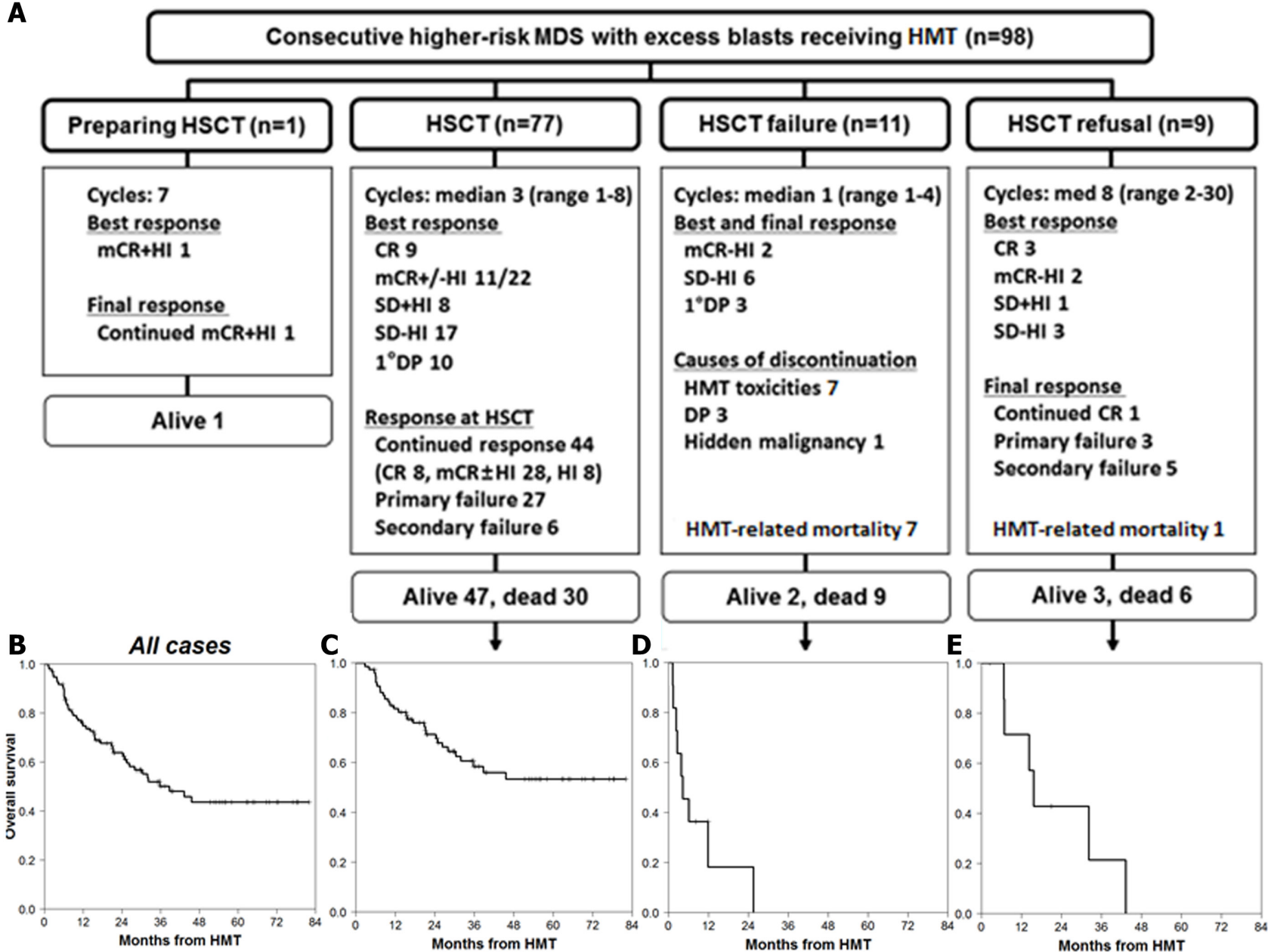

Figure 1: Response and survival from HMT initiation in higher-risk MDS patients with excess blasts. A. Summary of clinical responses during HMT according to the four groups observed: one patient in preparation for HSCT, 77 patients undergoing HSCT, 11 patients who became HSCT ineligible (HSCT failure), and 9 patients who refused to receive HSCT. Kaplan-Meier survival from HMT of B. all 98 patients, C. HSCT group, D. HSCT failure group, and E. HSCT refusal group. 
Table 1: Clinical characteristics of transplanted patients

\begin{tabular}{|c|c|c|c|c|}
\hline Variable & $\begin{array}{c}\text { All } \\
(n=77)\end{array}$ & $\begin{array}{l}\text { Marrow response } \\
(n=36)\end{array}$ & $\begin{array}{l}\text { No marrow } \\
\text { response } \\
(n=41)\end{array}$ & $\boldsymbol{P}$ \\
\hline Age at HMT (years); median (range) & $51(21-65)$ & $46(21-65)$ & $54(25-64)$ & 0.005 \\
\hline Age at HSCT (years); median (range) & $51(21-65)$ & $46(21-65)$ & $55(26-65)$ & 0.009 \\
\hline \multicolumn{5}{|l|}{ Sex, $n(\%)$} \\
\hline Male, & $48(62.3)$ & $16(44.4)$ & $32(78.0)$ & \\
\hline Female & $29(37.7)$ & $20(55.6)$ & $9(22.0)$ & 0.002 \\
\hline Days from higher-risk diagnosis to HMT, median (range) & $19.0(1-180)$ & $12(1-180)$ & $21(1-106)$ & 0.356 \\
\hline Days from HMT to HSCT, median (range) & $128(46-377)$ & $121(46-335)$ & $135(63-377)$ & 0.564 \\
\hline \multicolumn{5}{|l|}{ Hypomethylating agents } \\
\hline Azacitidine & $50(64.9)$ & $20(55.6)$ & $30(73.2)$ & \\
\hline Decitabine & $27(35.1)$ & $16(44.4)$ & $11(26.8)$ & 0.106 \\
\hline Cycles of HMT before HSCT, median (range) & $3(1-8)$ & $3(1-8)$ & $3(1-6)$ & 0.466 \\
\hline \multicolumn{5}{|l|}{ WHO classification at HMT, $n(\%)$} \\
\hline RAEB-1 & $16(20.8)$ & $10(27.8)$ & $6(14.6)$ & \\
\hline RAEB-2 & $59(76.6)$ & $25(69.4)$ & $34(82.9)$ & \\
\hline CMMoL-1 & $1(1.3)$ & - & $1(2.4)$ & \\
\hline CMMoL-2 & $1(1.3)$ & $1(2.8)$ & - & 0.358 \\
\hline \multicolumn{5}{|l|}{ Hemogram at HMT, median (range) } \\
\hline $\mathrm{WBC}, \times 10^{9} / \mathrm{L}$ & $2.41(0.26-74.4)$ & $2.54(0.78-36.5)$ & $2.32(0.26-74.4)$ & 0.593 \\
\hline $\mathrm{ANC}, \mathrm{x} 10^{9} / \mathrm{L}$ & $0.83(0.03-16.8)$ & $0.89(0.07-13.5)$ & $0.79(0.03-16.8)$ & 0.272 \\
\hline Hemoglobin, $\mathrm{d} / \mathrm{gL}$ & $8.4(3.5-15.5)$ & $8.4(3.8-11.9)$ & $8.4(3.5-15.5)$ & 0.451 \\
\hline Platelet, $\times 10^{9} / \mathrm{L}$ & $62(5-883)$ & $68(5-339)$ & $59(5-883)$ & 0.226 \\
\hline BM blast at HMT, median (range) & $12.0(5.8-19.1)$ & $12.0(6.0-19.1)$ & $13.0(5.8-19.0)$ & 0.613 \\
\hline \multicolumn{5}{|l|}{ IPSS cytogenetic risk at HMT, $n(\%)$} \\
\hline Good & $35(45.5)$ & $15(41.7)$ & $20(48.8)$ & \\
\hline Intermediate & $25(32.5)$ & $13(36.1)$ & $12(29.3)$ & \\
\hline Poor & $17(22.1)$ & $8(22.2)$ & $9(22.0)$ & 0.686 \\
\hline \multicolumn{5}{|l|}{ Transfusion dependency at HSCT, $n(\%)$} \\
\hline Yes & $45(58.4)$ & $16(44.4)$ & $29(70.7)$ & \\
\hline No & $32(41.6)$ & $20(55.6)$ & $12(29.3)$ & 0.020 \\
\hline \multicolumn{5}{|l|}{ Donor/recipient sex combination, $n(\%)$} \\
\hline Female $\rightarrow$ Male & $16(20.8)$ & $5(13.9)$ & $11(26.8)$ & \\
\hline Others & $61(79.2)$ & $31(86.1)$ & $30(73.2)$ & 0.163 \\
\hline \multicolumn{5}{|l|}{ Donor type, $n(\%)$} \\
\hline HLA-matched sibling donor & $35(45.5)$ & $15(41.7)$ & $20(48.8)$ & \\
\hline HLA-matched unrelated donor & $17(22.1)$ & $9(25.0)$ & $8(19.5)$ & \\
\hline Partially HLA-mismatched unrelated donor & $6(7.8)$ & $4(11.1)$ & $2(4.9)$ & \\
\hline Haploidentical related donor & $19(24.7)$ & $8(22.2)$ & $11(26.8)$ & 0.885 \\
\hline \multicolumn{5}{|l|}{ Conditioning intensity, $n(\%)$} \\
\hline MAC & $54(70.1)$ & $24(66.7)$ & $30(73.2)$ & \\
\hline RIC & $23(29.9)$ & $12(33.3)$ & $11(26.8)$ & 0.534 \\
\hline \multicolumn{5}{|l|}{ HMT response at HSCT, $n(\%)$} \\
\hline $\mathrm{CR}$ & $8(10.4)$ & $8(22.2)$ & - & \\
\hline $\mathrm{mCR}+\mathrm{HI}$ & $11(14.3)$ & $11(30.6)$ & - & \\
\hline mCR-HI & $17(2.1)$ & $17(47.2)$ & - & \\
\hline $\mathrm{SD}+\mathrm{HI}$ & $8(10.4)$ & - & $8(19.5)$ & \\
\hline SD-HI & $17(22.1)$ & - & $17(41.5)$ & \\
\hline Primary DP & $10(13.0)$ & - & $10(24.4)$ & \\
\hline Secondary failure & $6(7.8)$ & - & $6(14.6)$ & NE \\
\hline
\end{tabular}

HSCT, hematopoietic stem cell transplantation; HMT, hypomethylating treatment; WHO, World Health Organization; RAEB1 , refractory anemia of excess blast -1; RAEB-2, refractory anemia of excess blast-2; CMMoL-1, chronic myelomonocytic leukemia-1; CMMoL-2, chronic myelomonocytic leukemia-2; WBC, white blood cell; ANC, absolute neutrophil count; BM, bone marrow; IPSS, International Prognostic Scoring System; MAC, myeloablative conditioning; RIC, reduced-intensity conditioning; CR, complete remission; mCR, marrow complete remission; SD, stable disease; HI, hematologic improvement; DP, disease progression.

* The WHO diagnoses in all patients $(n=98)$, including those not receiving HSCT $(n=21)$, were RAEB-1 $(n=20)$, RAEB-2 $(n=73)$, CMMoL-1 $(n=1)$, and CMMoL-2 $(n=4)$. 
"marrow response" $(n=36)$ and "no marrow response" $(n=41)$. The baseline characteristics of these two groups are compared in Table 1. The two groups demonstrated significant differences in the 4-year probabilities of DFS $(P<0.001$; Figure 3A), OS $(P<0.001$; Figure 3B), CIR $(P<0.001$; Figure 3C), and CITRM $(P=0.001$; Figure $3 \mathrm{D})$. When similar analyses were performed according to marrow blast count at HMT, significantly better DFS rates were observed among patients with blast levels of $>5 \%$ and $<10 \%$ (marrow response: $88.9 \% \pm 10.5 \%$ vs. no marrow response: $37.5 \% \pm 17.1 \%, P=0.003$; Figure $4 \mathrm{~A})$ and patients with blast levels of $\geq 10 \%(91.7 \% \pm 5.6 \%$ vs. $9.5 \% \pm 8.1 \%, P<0.001$; Figure 4B). Table 2 lists the influence of variables on transplant outcomes in univariate analysis. In multivariate analysis (Table 3), no marrow response at HSCT was a significant predictor for inferior OS (hazard ratio [HR]: 12.6, $P<0.001$ ), DFS (HR: 10.2, $P<0.001$ ), CIR (HR: $8.5, P=0.004)$, and CITRM (HR: $8.6, P=0.002)$. In addition, poor cytogenetic risk [15] at HSCT was a significant predictor of inferior OS (HR: 2.9, $P=0.018$ ), DFS (HR: $3.7, P=0.003$ ), and CIR (HR: 5.0, $P=0.002)$. Based on these results, we evaluated the combined value of cytogenetic risk and continued marrow response for predicting HSCT outcomes, illustrated in Supplementary Figure 1A-1D.

\section{Predictors of marrow response or TRM after HMT}

Univariate and multivariate analyses of the impact of clinical variables at HMT on achievement of marrow response and HMT-related mortality in entire cohort ( $n$ $=98$ ) are summarized in Supplementary Table 1. The presence of peripheral blood (PB) blasts was associated with unfavorable marrow response compared to patients without PB blasts (odds ratio: 0.33, 95\% CI: 0.12-0.93, $P=0.04)$. None of the variables was independently associated with HMT-related mortality, although poor cytogenetic risk was a potential prognostic factor. These unfavorable impacts of PB blasts were further translated into differences in 4-year OS in entire cohort $(20.5 \%$ $\pm 11.0 \%$ vs. $52.0 \% \pm 6.9 \%, P=0.002$; Supplementary Figure 2A) as well as in transplant recipients $(22.0 \% \pm$ $12.6 \%$ vs. $61.7 \% \pm 7.1 \%, P<0.001$; Supplementary Figure 2B).

\section{DISCUSSION}

Advanced disease status at HSCT has a clear negative effect on the post-transplantation relapse rate, which is particularly evident among patients with higherrisk $\operatorname{MDS}[16,17]$. Although AML-type induction chemotherapy to reduce disease burden before transplant could be used aiming at reducing relapse rates [18], the role of pre-HSCT intensive therapy remains controversial $[19,20]$, as the improved relapse rates may be offset by significant toxicities. Furthermore, the related analyses supporting pre-HSCT induction chemotherapy are subject to an inherent selection bias, being related to the considerable proportion of patients with induction chemotherapy rendered ineligible for HSCT [21]. Therefore, the selection of pre-transplant bridging regimen should be essentially focused on preventing disease
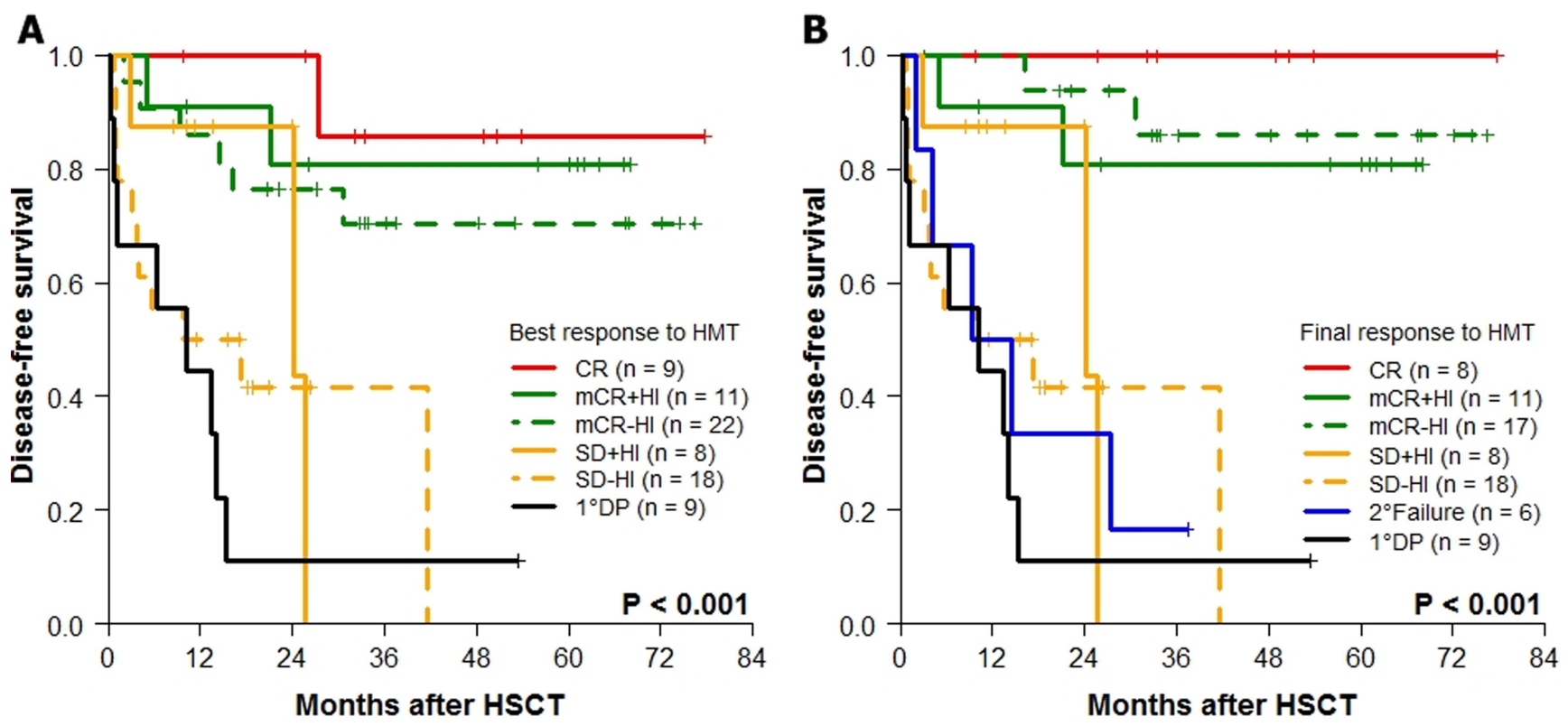

Figure 2: Kaplan-Meier analyses for DFS according to HMT response $(\boldsymbol{n}=\mathbf{7 7})$. DFS according to A. the best response and B. the final response to HMT. 

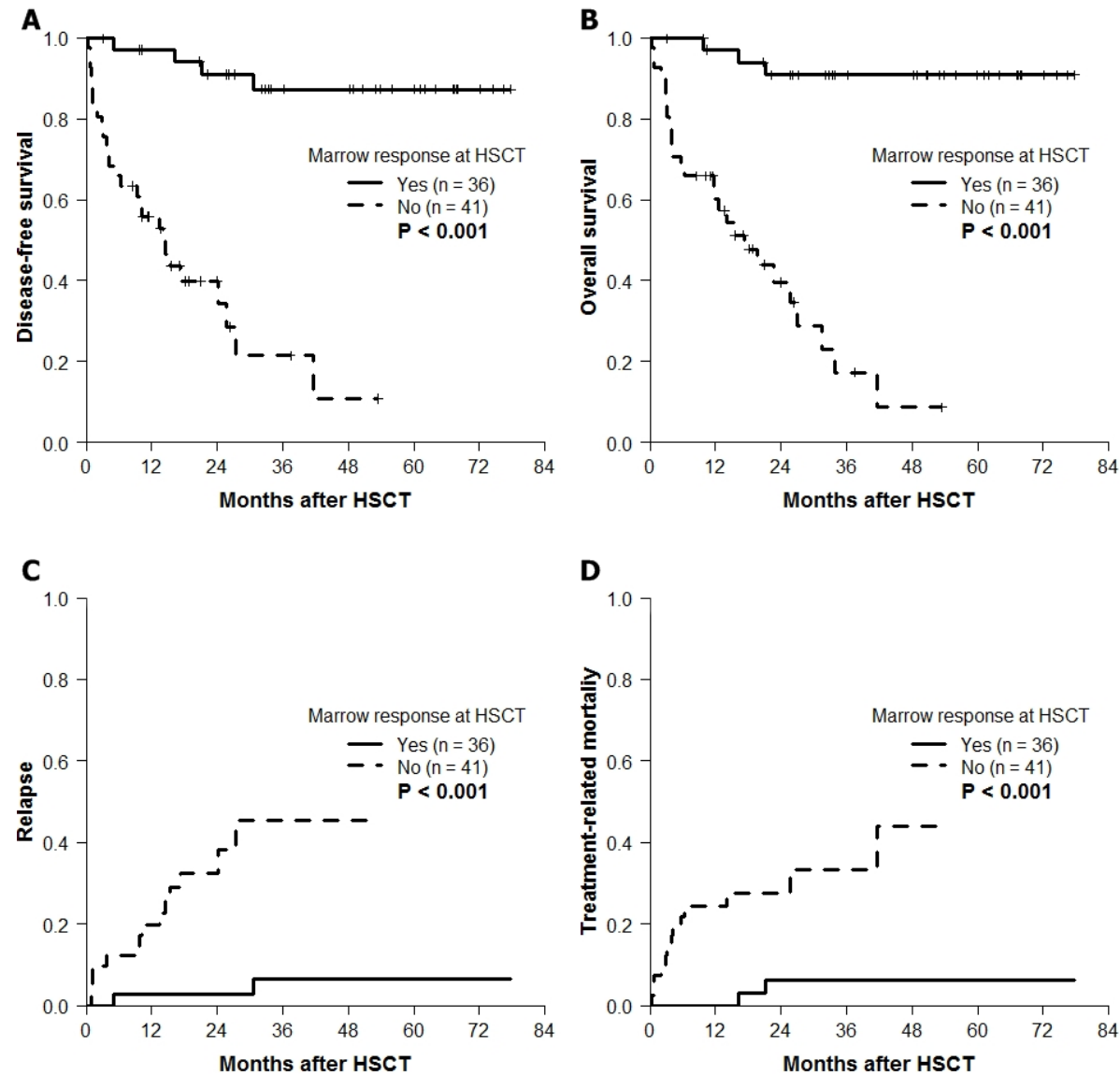

Figure 3: Posttransplantation outcome according to continued marrow response to HMT at HSCT $(n=77)$. We dichotomized patients into two groups according to the achievement of marrow response that sustained until the time of transplantation: marrow response $(n=36)$ and no marrow response $(n=41)$. The two groups demonstrated significant differences in the probabilities of A. DFS $(87.3 \% \pm 6.0 \%$ vs. $10.7 \% \pm 8.8 \%)$, B. OS $(90.9 \% \pm 5.0 \% v s .8 .6 \% \pm 7.4 \%)$, C. cumulative incidence of relapse $(6.5 \% \pm 4.6 \% v s$. $45.4 \% \pm 10.9 \%)$, and D. cumulative incidence of TRM $(6.2 \% \pm 4.3 \%$ vs. $43.9 \% \pm 13.7 \%)$.
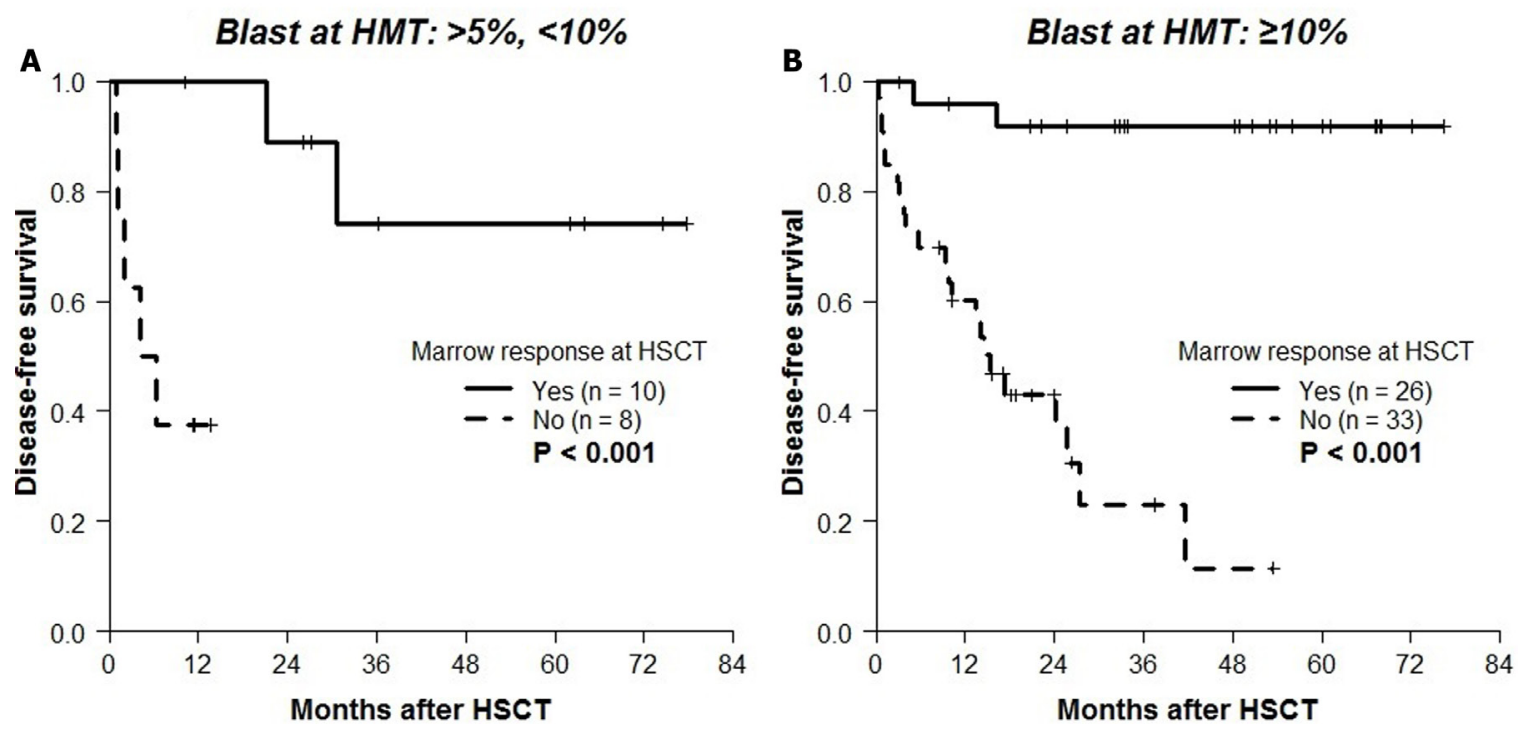

Figure 4: Kaplan-Meier analyses for DFS according to marrow response to HMT at HSCT in patient groups subdivided by marrow blast at HMT. DFS according to marrow response at HSCT in A. 18 patients with blast counts of $>5 \%$ and $<10 \%$ (marrow response: $88.9 \% \pm 10.5 \%$ vs. no marrow response: $37.5 \% \pm 17.1 \%, P=0.003)$ and in B. 59 patients with blast counts of $\geq 10 \%$ blasts $(91.7 \%$ $\pm 5.6 \%$ vs. $9.5 \% \pm 8.1 \%, P<0.001)$. 
Table 2: Univariate analysis of factors affecting the 4-year OS, DFS, CIR and CITRM after transplantation

\begin{tabular}{|c|c|c|c|c|c|c|c|c|c|}
\hline \multirow[b]{2}{*}{ Variables } & \multirow[b]{2}{*}{ No. } & \multirow{2}{*}{$\begin{array}{c}\text { OS } \\
\%\end{array}$} & \multicolumn{3}{|c|}{ DFS } & \multirow{2}{*}{$\begin{array}{c}\text { CIR } \\
\%\end{array}$} & \multicolumn{3}{|c|}{ CITRM } \\
\hline & & & $P$ & $\%$ & $\boldsymbol{P}$ & & $\boldsymbol{P}$ & $\%$ & $P$ \\
\hline Response at $\mathrm{HSCT}$ & & & $<0.001$ & & $<0.001$ & & $<0.001$ & & $<0.001$ \\
\hline Marrow response & 36 & $90.9 \pm 5.0$ & & $87.3 \pm 6.0$ & & $6.5 \pm 4.6$ & & $6.2 \pm 4.3$ & \\
\hline No marrow response & 41 & $8.7 \pm 7.4$ & & $10.7 \pm 8.8$ & & $45.4 \pm 10.9$ & & $43.9 \pm 13.7$ & \\
\hline Drugs & & & 0.077 & & 0.145 & & 0.447 & & 0.342 \\
\hline Decitabine & 27 & $66.2 \pm 10.2$ & & $62.0 \pm 10.5$ & & $25.9 \pm 7.3$ & & $18.0 \pm 9.0$ & \\
\hline Azacitidine & 50 & $45.8 \pm 8.6$ & & $48.5 \pm 8.3$ & & $25.9 \pm 7.3$ & & $25.7 \pm 7.1$ & \\
\hline Age at HSCT, years & & & 0.049 & & 0.047 & & 0.184 & & 0.278 \\
\hline$<52$ & 39 & $63.7 \pm 8.7$ & & $65.1 \pm 8.4$ & & $16.7 \pm 6.4$ & & $18.1 \pm 7.1$ & \\
\hline$\geq 52$ & 38 & $43.5 \pm 9.6$ & & $40.3 \pm 9.7$ & & $33.5 \pm 9.6$ & & $26.3 \pm 8.0$ & \\
\hline Sex & & & 0.013 & & 0.025 & & 0.219 & & 0.128 \\
\hline Female & 29 & $75.2 \pm 9.2$ & & $71.6 \pm 9.5$ & & $18.1 \pm 8.7$ & & $10.3 \pm 8.3$ & \\
\hline Male & 48 & $40.5 \pm 8.6$ & & $42.4 \pm 8.5$ & & $27.1 \pm 6.9$ & & $30.5 \pm 5.8$ & \\
\hline IPSS at start of HMT & & & 0.283 & & 0.343 & & 0.630 & & 0.532 \\
\hline Intermediate-2 & 56 & $59.0 \pm 7.3$ & & $57.9 \pm 7.2$ & & $22.7 \pm 6.3$ & & $19.4 \pm 6.3$ & \\
\hline High & 21 & $39.6 \pm 13.6$ & & $42.1 \pm 13.4$ & & $27.4 \pm 11.3$ & & $30.5 \pm 13.4$ & \\
\hline IPSS cytogenetic risk at HSCT & & & 0.004 & & 0.001 & & 0.002 & & 0.873 \\
\hline Good/Intermediate & 64 & $62.4 \pm 7.1$ & & $60.8 \pm 7.2$ & & $14.5 \pm 5.4$ & & $22.0 \pm 6.1$ & \\
\hline Poor & 13 & $23.1 \pm 11.7$ & & $23.1 \pm 11.7$ & & $53.9 \pm 15.0$ & & $23.1 \pm 12.7$ & \\
\hline Transfusion dependency at HSCT & & & 0.006 & & 0.002 & & 0.002 & & 0.517 \\
\hline Yes & 45 & $41.5 \pm 8.1$ & & $40.2 \pm 8.0$ & & $35.5 \pm 7.6$ & & $24.3 \pm 7.1$ & \\
\hline No & 32 & $73.4 \pm 9.1$ & & $75.0 \pm 9.1$ & & $5.0 \pm 5.0$ & & $20.0 \pm 8.4$ & \\
\hline Donor/recipient sex combination & & & 0.976 & & 0.983 & & 0.545 & & 0.535 \\
\hline Female $\rightarrow$ Male & 16 & $50.3 \pm 15.6$ & & $53.4 \pm 7.2$ & & $28.0 \pm 12.7$ & & $13.7 \pm 9.4$ & \\
\hline Others & 61 & $54.5 \pm 7.2$ & & $58.3 \pm 13.3$ & & $22.6 \pm 6.0$ & & $24.1 \pm 6.2$ & \\
\hline Donor type" & & & 0.757 & & 0.684 & & 0.180 & & 0.441 \\
\hline Conventional & 52 & $41.7 \pm 30.4$ & & $49.7 \pm 8.3$ & & $28.8 \pm 7.1$ & & $21.5 \pm 7.0$ & \\
\hline Alternative & 25 & $51.3 \pm 8.3$ & & $60.6 \pm 10.5$ & & $13.9 \pm 7.8$ & & $25.5 \pm 9.4$ & \\
\hline Conditioning Intensity & & & 0.561 & & 0.518 & & 0.256 & & 0.769 \\
\hline RIC & 23 & $60.3 \pm 11.2$ & & $61.9 \pm 10.8$ & & $15.1 \pm 8.4$ & & $23.0 \pm 9.4$ & \\
\hline MAC & 54 & $51.0 \pm 8.2$ & & $49.4 \pm 8.2$ & & $27.9 \pm 7.0$ & & $22.7 \pm 7.0$ & \\
\hline HCT-CI risk & & & 0.156 & & 0.109 & & 0.539 & & 0.071 \\
\hline Low/ Intermediate & 45 & $59.3 \pm 8.5$ & & $61.7 \pm 8.1$ & & $21.3 \pm 7.0$ & & $15.0 \pm 5.9$ & \\
\hline High & 32 & $43.2 \pm 10.3$ & & $38.7 \pm 10.6$ & & $27.2 \pm 8.6$ & & $36.6 \pm 10.6$ & \\
\hline
\end{tabular}

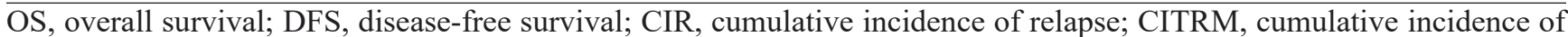
treatment-related mortality; HSCT, hematopoietic stem cell transplantation; IPSS, International Prognostic Scoring System; HMT, hypomethylating treatment; RIC, reduced-intensity conditioning; MAC, myeloablative conditioning; HCT-CI, hematopoietic cell transplant- co-morbidity index.

*Conventional donor included HLA-matched sibling or unrelated donor; Alternative donor included partially HLA-mismatched or haploidentical related donor.

progression and toxicity that would interfere in proceeding to HSCT, while inducing disease "debulking" (ideally within a few months) translating into improved transplant survival.

Although HMT is reported to have low toxicity, there are no reports regarding its toxicity during preparation for transplantation and the subsequent HSCT success rate. Therefore, to provide clinically relevant information, and to minimize selection bias, we screened all patients who received HMT for higher-risk MDS with excess blasts, and only excluded patients who were ineligible for HSCT. Our analyses revealed that bridging failure occurred in $11 \%$ of the patients with pre-HSCT HMT, and that $8 \%$ experienced HMT-related mortality. These results compare favorably with the higher mortality rate of $16 \%$ during the induction chemotherapy among carefully screened patients who were to undergo HSCT in a prospective clinical trial [22]. The relatively low HMTrelated mortality rate in our study suggested that HMT is a feasible pre-transplant option.

Disease stage at the time of transplantation has been known as one of the most important factors that influence outcome after allogeneic HSCT [17, 18, 23]. However, a recent study by Potter et al. using a large registry data suggested that, unlike for patients with primary refractory disease, the post-transplant outcomes of patients with MDS not in CR were not significantly worse than those in CR [24]. This is in line with our results which showed that continued marrow response even without HI at HSCT was an independent predictor of a favorable prognosis, 
Table 3: Multivariate analysis of factors affecting the 4-year OS, DFS, CIR and CITRM after transplantation

\begin{tabular}{|c|c|c|c|c|c|c|c|c|}
\hline \multirow[b]{2}{*}{ Variables } & \multirow{2}{*}{$\frac{\text { OS }}{\text { HR }(95 \% \mathrm{CI})}$} & \multicolumn{3}{|c|}{ DFS } & \multicolumn{2}{|l|}{ CIR } & \multicolumn{2}{|l|}{ CITRM } \\
\hline & & $P$ & HR $(95 \%$ CI) & $\boldsymbol{P}$ & HR $(95 \%$ CI) & $\boldsymbol{P}$ & HR $(95 \%$ CI $)$ & $\boldsymbol{P}$ \\
\hline \multicolumn{9}{|l|}{ Response at HSCT } \\
\hline Marrow response & 1 & & 1 & & 1 & & 1 & \\
\hline No marrow response & $12.6(3.5-45.4)$ & $<0.001$ & $10.2(3.3-31.8)$ & $<0.001$ & $8.5(2.0-36.7)$ & 0.004 & $8.6(2.2-34.2)$ & 0.002 \\
\hline \multicolumn{9}{|c|}{ IPSS cytogenetic risk at $\mathrm{HSCT}$} \\
\hline Good/Intermediate & 1 & & 1 & & 1 & & - & \\
\hline Poor & $2.9(1.2-6.9)$ & 0.018 & $3.7(1.5-8.7)$ & 0.003 & $5.0(1.8-13.8)$ & 0.002 & & \\
\hline \multicolumn{9}{|l|}{ Age at HSCT, years } \\
\hline$<52$ & 1 & & 1 & & - & & - & \\
\hline$\geq 52$ & $2.3(1.0-5.4)$ & 0.066 & $2.3(1.0-5.4)$ & 0.055 & & & & \\
\hline \multicolumn{9}{|l|}{ HCT-CI risk } \\
\hline Low/ Intermediate & - & & - & & - & & 1 & \\
\hline High & & & & & & & $2.5(0.9-6.9)$ & 0.068 \\
\hline \multicolumn{9}{|l|}{ Sex } \\
\hline Male & 1 & & 1 & & - & & - & \\
\hline Female & $0.9(0.3-2.2)$ & 0.745 & $0.9(0.4-2.2)$ & 0.876 & & & & \\
\hline \multicolumn{9}{|c|}{ Transfusion dependency at HSCT } \\
\hline Yes & 1 & & 1 & & - & & - & \\
\hline No & $2.2(0.8-6.0)$ & 0.109 & $2.6(1.0-6.7)$ & 0.055 & & & & \\
\hline
\end{tabular}

OS, overall survival; DFS, disease-free survival; CIR, cumulative incidence of relapse; CITRM, cumulative incidence of treatment-related mortality; HR, hazard ratio; CI, confidence interval; HSCT, hematopoietic stem cell transplantation; IPSS, International Prognostic Scoring System; HCT-CI, hematopoietic cell transplant- co-morbidity index.

and that $\mathrm{CR}$ was not a prerequisite for prolonged survival. Furthermore, the acquisition of HI only without marrow response did not translate into a survival benefit in our transplantation setting. This finding is interesting, because it conflicts with the survival benefit from the achievement of HI in the HMT-only setting [25]. Similarly, in our previous report, the positive effect of marrow response with or without HI after HMT on post-transplant DFS was mainly evident in patients classified as higher-risk MDS before HMT while achievement of HI was the main response type in lower-risk MDS [11], suggesting that the influences of HMT response at HSCT vary according to pre-HMT risk groups. The controversies regarding the relationship between HMT response and post-transplantation survival may be explained by the heterogeneity in the time of response assessment, whether or not $\mathrm{HI}$ is included for definition of overall response, and different response patterns according to pre-HMT risk groups $[9,11,26]$. Future studies are needed to determine the role of pre-transplant achievement of $\mathrm{HI}$ by HMT in comparison with upfront HSCT, as worsening of cytopenias from pre-HSCT HMT aimed to achieve HI in patients with low blast counts may increase their risk of infectious complications [27].

The present study revealed that 50 of the 98 cases experienced marrow response after a median of 2 cycles (range: 1-9 cycles), and that the cumulative marrow response rates after 2 cycles, 3 cycles, and 4 cycles were $68 \%, 84 \%$, and $96 \%$, respectively. The relatively high marrow response rate in our study may be associated with the frequent marrow assessments. Moreover, the frequent response evaluation was helpful for immediately identifying patients who had achieved a short-term marrow response followed by a rapid increments in marrow blasts. In fact, secondary failure typically occurred at approximately 1 month after achieving marrow response, and 5 of the 6 patients with secondary failure died due to relapse $(n=3)$ or TRM $(n=2)$. These findings suggest that it is important to maintain continued marrow response until HSCT. According to the interim results of a recent prospective Italian multicenter trial which was designed to complete at least 4 cycles of pre-HSCT azacitidine treatment before transplant, approximately $48 \%$ of the enrolled patients could not proceed to HSCT due to reasons including disease relapse/ progression (35\%) or adverse events (27\%)[28]. Thus, unlike in nontransplantation setting [25, 29], once marrow response has been achieved, immediate HSCT seems most effective to increase the likelihood of cases with higher-risk MDS and excess blasts reaching transplantation with favorable post-transplant outcomes, rather than to continue on HMT beyond time of marrow response. Moreover, response to HMT may reflect the innate sensitivity of the MDS clone, and HMT-induced drug resistance or selection of a resistant clone should be considered, as it may become more likely after continued treatment [30]. The influence of mCR upon survival was recently suggested in a study of decitabine treatment [31], although our results may 
provide the first evidence regarding the importance of marrow response in enhancing HSCT outcomes for higher-risk MDS with excess blasts.

Our strategy of pre-transplant "debulking" treatment with hypomethylating agent that was immediately followed by HSCT seems to provide favorable posttransplant outcomes. The median survival duration was 39.3 months after HMT among all patients in this study, which is superior to the reported 18-25 months after azacitidine or 5-day decitabine treatment [21, 32-34], showing the well-known effect of HSCT in higher-risk MDS [35]. And also, the beneficial role of HSCT might have been enhanced by pre-HSCT HMT, as our 4-year DFS rate after HSCT (54\%) was superior to those from previous studies (15-30\%) [4]. Furthermore, although we only evaluated patients with higher-risk MDS and excess blasts ( $>5 \%$ ), the survival rate was comparable to that observed in recent HSCT analyses encompassing both lower- and higher-risk MDS [8, 10, 36], suggesting that HMT pre-treatment before HSCT is feasible. We also assume that, for those patients with lack of a matched related or unrelated donor, our approach of immediately proceeding to haploidentical-related transplant may have contributed to the favorable outcomes in our study $[3,37]$.

Previous studies have reported that HMT response could be predicted by several clinical parameters, such as white blood cell count, platelet count, karyotype, and marrow blast count $[13,38,39]$. In agreement with a recent study conducted on a large registry data [40], the presence of PB blasts was the only independent predictor of poor marrow response, which was associated with inferior survival in our study. Thus, while pre-HSCT HMT could be preferred in patients without PB blasts, up-front HSCT or pre-HSCT intensive chemotherapy could be considered for patients with $\mathrm{PB}$ blasts. In addition to marrow response at HSCT, poor karyotype was also a risk factor for relapse and poor survival. Thus, marrow response, PB blast detection, and karyotyping may be useful for selecting pre-HSCT treatment option and patients who are most appropriate for HSCT. Mutations in certain genes may be useful for prediction of posttransplantation survival, particularly in patients with complex karyotypes (e.g., by assessing TP53) [41, 42], although these markers require further studies for prediction of HMT response [39, 4345]. Future clinical trial might be useful for developing and evaluating a stepwise decision-making model that is based on these risk factors.

In conclusion, the findings of our study indicate that the sequential treatment using HMT followed immediately by HSCT is feasible and offers an efficient treatment strategy for higher-risk MDS patients with excess blasts. Notably, the achievement of marrow response by pre-HSCT HMT and proceeding to transplant while maintaining the response was significantly associated with lower incidences of relapse and TRM and improved DFS. These results suggest that, once marrow response is achieved during HMT, immediate HSCT rather than continuing HMT should be considered for patients with higher-risk MDS and excess blasts. The development of clinical and molecular tools for earlier recognition of HMT response may also optimize selecting transplant candidates and timing. Whether pre-HSCT HMT offers advantages over upfront HSCT and intensive chemotherapy in higherrisk patient, especially those with excess blasts, needs to be confirmed by randomized trials.

\section{PATIENTS AND METHODS}

\section{Patient selection}

All adult patients with MDS who were eligible for HSCT were retrospectively screened to identify cases with higher-risk MDS and excess marrow blasts that received pre-HSCT HMT between January 2009 and June 2015 at the Catholic Blood and Marrow Transplantation Center (Seoul, Korea). We analyzed the patients receiving HMT for MDS with marrow blast levels of $>5 \%$ and intermediate-2 or high-risk group according to the International Prognostic Scoring System [15], regardless of the patient's intention to undergo HSCT. The selection criteria for HSCT eligibility included an age of $\leq 65$ years, an ECOG performance status of $\leq 2$, and no major organ failure. This study was approved by the institutional review board of the Seoul St. Mary's Hospital at the Catholic University of Korea, and complied with the tenets of the Declaration of Helsinki.

\section{Treatment strategy and procedures}

All patients received a standard HMT regimen of azacitidine $\left(75 \mathrm{mg} / \mathrm{m}^{2} /\right.$ day for 7 days) or decitabine (20 $\mathrm{mg} / \mathrm{m}^{2} /$ day for 5 days). According to our institution's guidelines regarding HSCT for higher-risk MDS, transplantation was performed immediately after a donor was available, regardless of the treatment cycle or response to HMT. When patients experienced secondary AML after HMT, induction chemotherapy was administered when patients were judged to be able to tolerate the intensive treatment. For conventional donor HSCT, the patients underwent a preparative regimen of fludarabine (150 $\mathrm{mg} / \mathrm{m}^{2}$ ) with 2 days or 4 days of intravenous busulfan $(3.2 \mathrm{mg} / \mathrm{kg} / \mathrm{day})$ and rabbit anti-thymocyte globulin (ATG; 5-10 mg/kg; Genzyme, Cambridge, MA). For haploidentical related donor transplantation, the patients underwent regimens of fludarabine $\left(150 \mathrm{mg} / \mathrm{m}^{2}\right)$ with 2 days of intravenous busulfan $(3.2 \mathrm{mg} / \mathrm{kg} /$ day $)$, total body irradiation (800 cGy or $400 \mathrm{cGy})$, and ATG $(5.0 \mathrm{mg} / \mathrm{kg}$ ). GVHD prophylaxis was performed using short-course methotrexate $\left(10 \mathrm{mg} / \mathrm{m}^{2}\right.$ intravenous bolus on days $+1,+3$, +6 , and +11 ) plus cyclosporine for related donor HSCT or 
tacrolimus for unrelated/haploidentical donor HSCT. The protocol for the transplantation procedures was the same, with the exception of the conditioning step and general transplantation procedures being performed as previously described [11, 46]. All of the transplanted patients received PB stem cells.

\section{Definitions}

Bone marrow aspiration and biopsy were performed after every 2 HMT cycles, based on the clinical needs, and immediately before conditioning. Hematological responses were only assessed when bone marrow was obtained, and HI was assessed whenever complete blood cell counting was performed, using the International Working Group 2006 response criteria [47]. The best and final responses (at HSCT) were defined as CR, partial remission, $\mathrm{mCR}+\mathrm{HI}$, $\mathrm{mCR}-\mathrm{HI}$ or $\mathrm{SD}+\mathrm{HI}$. Patients with $\mathrm{CR} / \mathrm{mCR}$ with or without $\mathrm{HI}$ were designated as marrow response group. Non-responders and patients who had failed to maintain a previous response at the time of the HSCT were categorized as primary failure (SD-HI or primary DP) and secondary failure (loss of response or relapse), respectively [48]. Myeloid and platelet engraftment was defined as the first of 3 consecutive days with an absolute neutrophil count (ANC) of $\geq .5 \times 10^{9} / \mathrm{L}$ and the first of 7 consecutive days with a platelet count $\geq$ $20 \times 10^{9} / \mathrm{L}$ without transfusion, respectively. GVHD was diagnosed and graded according to the clinical consensus criteria $[49,50]$. The hematopoietic cell transplantationcomorbidity index was estimated according to Sorror et al. [51]. HMT-related mortality was arbitrarily defined as death that occurred due to any event during the 42 days after the final administration of HMT, in the absence of DP, which was assessed using marrow blast counts.

\section{Statistical analyses}

Differences in the categorical and continuous variables among the patient risk subgroups were compared using the $\chi 2$ test, Fisher's exact test, or Mann-Whitney's test, as appropriate. Time to event was assessed from the infusion day. Events for DFS were relapse or death from any cause, whereas death from any cause was a relevant event for OS. TRM was defined as death from any cause during continuous remission after HSCT. Survival curves for OS and DFS were plotted using the Kaplan-Meier method, and differences were evaluated using the log-rank test. The cumulative incidence of TRM and relapse were plotted and compared using the Gray test. The effects of the covariates on OS and DFS were determined using the Cox proportional hazard model. Factors were considered significant if they exhibited a $P$-value of $<0.05$ in a twotailed likelihood ratio test. The effects of the covariates on the CIR and CITRM were determined using the semi-parametric proportional hazard model for the subdistribution of competing risks. The final models were created using the backward conditional method. Most statistical analyses were performed using SPSS software (version 13.0; SPSS Inc., Chicago, IL, USA), and the cumulative incidence analyses were performed using $\mathrm{R}$ software (http://cran.r-project.org/).

\section{ACKNOWLEDGMENTS}

The authors acknowledge all members at the Catholic Blood and Marrow Transplantation Center, particularly the house staff, for their good care of the patients.

\section{CONFLICTS OF INTEREST}

The authors report no potential conflicts of interest to disclose.

\section{GRANT SUPPORT}

This research was supported by the Basic Science Research Program through the National Research Foundation of Korea (NRF) funded by the Ministry of Science, ICT and future Planning (2015R1A2A2A04002756). Also, this study was partly supported by a grant from Sanofi Aventis, Korea.

\section{REFERENCES}

1. National Comprehensive Cancer Network (NCCN). NCCN Clinical Practice Guidelines in Oncology (NCCN guidelines). Myelodysplastic sydromes Version 1.2017. Available at: http://www.nccn.org/professionals/physician gls/pdf/mds.pdf. Accessed September 27, 2016.

2. Hahn T, McCarthy PL, Jr. Hassebroek A, Bredeson C, Gajewski JL, Hale GA, Isola LM, Lazarus HM, Lee SJ, Lemaistre CF, Loberiza F, Maziarz RT, Rizzo JD, et al. Significant improvement in survival after allogeneic hematopoietic cell transplantation during a period of significantly increased use, older recipient age, and use of unrelated donors. J Clin Oncol. 2013; 31: 2437-2449.

3. Shin SH, Kim JH, Jeon YW, Yoon JH, Yahng SA, Lee SE, Choi YS, Kim DY, Lee JH, Lee S, Kim HJ, Min CK, Lee JW, et al. Feasible outcomes of T cell-replete haploidentical stem cell transplantation with reduced-intensity conditioning in patients with myelodysplastic syndrome. Biol Blood Marrow Transplant. 2015; 21: 342-349.

4. Deeg HJ, Storer B, Slattery JT, Anasetti C, Doney KC, Hansen JA, Kiem HP, Martin PJ, Petersdorf E, Radich HP, Sanders JE, Shulman HM, Warren EH, et al. Conditioning with targeted busulfan and cyclophosphamide for hemopoietic stem cell transplantation from related and unrelated donors in patients with myelodysplastic 
syndrome. Blood. 2002; 100: 1201-1207.

5. Parmar S, de Lima M, Deeg HJ, Champlin R. Hematopoietic stem cell transplantation for myelodysplastic syndrome: a review. Semin Oncol. 2011; 38: 693-704.

6. Guardiola P, Runde V, Bacigalupo A, Ruutu T, Locatelli F, Boogaerts MA, Pagliuca A, Cornelissen JJ, Schouten HC, Carreras E, Finke J, van Biezen A, Brand R, et al. Retrospective comparison of bone marrow and granulocyte colony-stimulating factor-mobilized peripheral blood progenitor cells for allogeneic stem cell transplantation using HLA identical sibling donors in myelodysplastic syndromes. Blood. 2002; 99: 4370-4378.

7. Sierra J, Perez WS, Rozman C, Carreras E, Klein JP, Rizzo JD, Davies SM, Lazarus HM, Bredeson CN, Marks DI, Canals C, Boogaerts MA, Goldman J, et al. Bone marrow transplantation from HLA-identical siblings as treatment for myelodysplasia. Blood. 2002; 100: 1997-2004.

8. Field T, Perkins J, Huang Y, Kharfan-Dabaja MA, Alsina M, Ayala E, Fernandez HF, Janssen W, Lancet J, Perez L, Sullivan D, List A and Anasetti C. 5-Azacitidine for myelodysplasia before allogeneic hematopoietic cell transplantation. Bone Marrow Transplant. 2010; 45: 255260.

9. Damaj G, Duhamel A, Robin M, Beguin Y, Michallet M, Mohty M, Vigouroux S, Bories P, Garnier A, El Cheikh J, Bulabois CE, Huynh A, Bay JO, et al. Impact of azacitidine before allogeneic stem-cell transplantation for myelodysplastic syndromes: a study by the Societe Francaise de Greffe de Moelle et de Therapie-Cellulaire and the Groupe-Francophone des Myelodysplasies. J Clin Oncol. 2012; 30: 4533-4540.

10. Gerds AT, Gooley TA, Estey EH, Appelbaum FR, Deeg HJ and Scott BL. Pretransplantation Therapy with Azacitidine vs Induction Chemotherapy and Posttransplantation Outcome in Patients with MDS. Biol Blood Marrow Transplant. 2012; 18: 1211-1218.

11. Yahng SA, Yoon JH, Shin SH, Lee SE, Cho BS, Lee DG, Eom KS, Lee S, Min CK, Kim HJ, Cho SG, Kim DW, Lee JW, et al. Response to pretransplant hypomethylating agents influences the outcome of allogeneic hematopoietic stem cell transplantation in adults with myelodysplastic syndromes. Eur J Haematol. 2013; 90: 111-120.

12. Malcovati L, Hellstrom-Lindberg E, Bowen D, Ades L, Cermak J, Del Canizo C, Della Porta MG, Fenaux P, Gattermann N, Germing U, Jansen JH, Mittelman M, Mufti G, et al. Diagnosis and treatment of primary myelodysplastic syndromes in adults: recommendations from the European LeukemiaNet. Blood. 2013; 122: 2943 2964.

13. Itzykson R, Thepot S, Quesnel B, Dreyfus F, Beyne-Rauzy O, Turlure P, Vey N, Recher C, Dartigeas C, Legros L, Delaunay J, Salanoubat C, Visanica S, et al. Prognostic factors for response and overall survival in 282 patients with higher-risk myelodysplastic syndromes treated with azacitidine. Blood. 2011; 117: 403-411.
14. Lubbert M, Wijermans P, Kunzmann R, Verhoef G, Bosly A, Ravoet C, Andre M and Ferrant A. Cytogenetic responses in high-risk myelodysplastic syndrome following low-dose treatment with the DNA methylation inhibitor 5-aza-2'-deoxycytidine. Br J Haematol. 2001; 114: 349357.

15. Greenberg P, Cox C, LeBeau MM, Fenaux P, Morel P, Sanz G, Sanz M, Vallespi T, Hamblin T, Oscier D, Ohyashiki $\mathrm{K}$, Toyama K, Aul C et al. International scoring system for evaluating prognosis in myelodysplastic syndromes. Blood. 1997; 89: 2079-2088.

16. Warlick ED, Cioc A, Defor T, Dolan M and Weisdorf D. Allogeneic stem cell transplantation for adults with myelodysplastic syndromes: importance of pretransplant disease burden. Biol Blood Marrow Transplant. 2009; 15: $30-38$.

17. Kebriaei P, Kline J, Stock W, Kasza K, Le Beau MM, Larson RA and van Besien K. Impact of disease burden at time of allogeneic stem cell transplantation in adults with acute myeloid leukemia and myelodysplastic syndromes. Bone Marrow Transplant. 2005; 35: 965-970.

18. de Witte T, Hagemeijer A, Suciu S, Belhabri A, Delforge M, Kobbe G, Selleslag D, Schouten HC, Ferrant A, Biersack H, Amadori S, Muus P, Jansen JH et al. Intensive chemotherapy followed by allogeneic or autologous stem cell transplantation for patients with myelodysplastic syndromes (MDSs) and acute myeloid leukemia following MDS. Haematologica. 2010; 95: 1754-1761.

19. Nakai K, Kanda Y, Fukuhara S, Sakamaki H, Okamoto S, Kodera Y, Tanosaki R, Takahashi S, Matsushima T, Atsuta Y, Hamajima N, Kasai M, Kato S. Value of chemotherapy before allogeneic hematopoietic stem cell transplantation from an HLA-identical sibling donor for myelodysplastic syndrome. Leukemia. 2005; 19: 396-401.

20. Scott BL, Storer B, Loken MR, Storb R, Appelbaum FR, Deeg HJ Pretransplantation induction chemotherapy and posttransplantation relapse in patients with advanced myelodysplastic syndrome. Biol Blood Marrow Transplant. 2005; 11: 65-73.

21. Estey E, de Lima M, Tibes R, Pierce S, Kantarjian H, Champlin R and Giralt S. Prospective feasibility analysis of reduced-intensity conditioning (RIC) regimens for hematopoietic stem cell transplantation (HSCT) in elderly patients with acute myeloid leukemia (AML) and highrisk myelodysplastic syndrome (MDS). Blood. 2007; 109: 1395-1400.

22. de Witte T, Suciu S, Verhoef G, Labar B, Archimbaud E, Aul C, Selleslag D, Ferrant A, Wijermans P, Mandelli F, Amadori S, Jehn U, Muus P, et al. Intensive chemotherapy followed by allogeneic or autologous stem cell transplantation for patients with myelodysplastic syndromes (MDSs) and acute myeloid leukemia following MDS. Blood. 2001; 98: 2326-2331.

23. Lim Z, Brand R, Martino R, van Biezen A, Finke J, Bacigalupo A, Beelen D, Devergie A, Alessandrino 
E, Willemze R, Ruutu T, Boogaerts M, Falda M et al. Allogeneic hematopoietic stem-cell transplantation for patients 50 years or older with myelodysplastic syndromes or secondary acute myeloid leukemia. J Clin Oncol. 2010; 28: 405-411.

24. Potter VT, Iacobelli S, van Biezen A, Maertens J, Bourhis JH, Passweg JR, Yakhoub-AghaI, Tabrizi R, Bay JO, Chevallier P, Chalandon Y, Huynh A, Cahn JY et al. Comparison of Intensive Chemotherapy and Hypomethylating Agents before Allogeneic Stem Cell Transplantation for Advanced Myelodysplastic Syndromes: A Study of the Myelodysplastic Syndrome Subcommittee of the Chronic Malignancies Working Party of the European Society for Blood and Marrow Transplant Research. Biol Blood Marrow Transplant. 2016; 22: 1615-1620.

25. Fenaux P, Mufti GJ, Hellstrom-Lindberg E, Santini V, Finelli C, Giagounidis A, Schoch R, Gattermann N, Sanz G, List A, Gore SD, Seymour JF, Bennett JM, et al. Efficacy of azacitidine compared with that of conventional care regimens in the treatment of higher-risk myelodysplastic syndromes: a randomised, open-label, phase III study. The Lancet Oncol. 2009; 10: 223-232.

26. Kim DY, Lee JH, Park YH, Lee JH, Kim SD, Choi Y, Lee SB, Lee KH, Ahn SY, Lee YS, Seol M, Kang YA, Jeon $\mathrm{M}$, et al. Feasibility of hypomethylating agents followed by allogeneic hematopoietic cell transplantation in patients with myelodysplastic syndrome. Bone Marrow Transplant. 2012; 47: 374-379.

27. Merkel D, Filanovsky K, Gafter-Gvili A, Vidal L, Aviv A, Gatt ME, Silbershatz I, Herishanu Y, Arad A, Tadmor T, Dally N, Nemets A, Rouvio O, et al. Predicting infections in high-risk patients with myelodysplastic syndrome/acute myeloid leukemia treated with azacitidine: a retrospective multicenter study. Am J hematol. 2013; 88: 130-134.

28. Voso MT, Leone G, Piciocchi A, Fianchi L, Di Bartolomeo P, Candoni A, Criscuolo M, Masciulli A, Cerqui E, Molteni A, Finelli C, Parma M, Rivellini F, et al. Feasibililty of azacitidine as bridge to allogeneic stem cell transplantation in patients with higher-risk MDS or low-blast count AML: results of the BMT-AZA multicenter prospective Study. Blood. 2015; 126: abstr 66.

29. Silverman LR, Fenaux P, Mufti GJ, Santini V, HellstromLindberg E, Gattermann N, Sanz G, List AF, Gore SD and Seymour JF. Continued azacitidine therapy beyond time of first response improves quality of response in patients with higher-risk myelodysplastic syndromes. Cancer. 2011; 117: 2697-2702.

30. Bram EE, Stark M, Raz $S$ and Assaraf YG. Chemotherapeutic drug-induced ABCG2 promoter demethylation as a novel mechanism of acquired multidrug resistance. Neoplasia. 2009; 11: 1359-1370.

31. Jung HA, Maeng CH, Kim M, Kim S, Jung CW and Jang JH. Platelet response during the second cycle of decitabine treatment predicts response and survival for myelodysplastic syndrome patients. Oncotarget. 2015; 6:
16653-16662. doi: 10.18632/oncotarget.3914.

32. Silverman LR, Demakos EP, Peterson BL, Kornblith AB, Holland JC, Odchimar-Reissig R, Stone RM, Nelson D, Powell BL, DeCastro CM, Ellerton J, Larson RA, Schiffer $\mathrm{CA}$ et al. Randomized controlled trial of azacitidine in patients with the myelodysplastic syndrome: a study of the cancer and leukemia group B. J Clin Oncol. 2002; 20: 2429-2440.

33. Steensma DP, Baer MR, Slack JL, Buckstein R, Godley LA, Garcia-Manero G, Albitar M, Larsen JS, Arora S, Cullen MT and Kantarjian H. Multicenter study of decitabine administered daily for 5 days every 4 weeks to adults with myelodysplastic syndromes: the alternative dosing for outpatient treatment (ADOPT) trial. J Clin Oncol. 2009; 27: $3842-3848$.

34. Lee JH, Jang JH, Park J, Park S, Joo YD, Kim YK, Kim HG, Choi CW, Kim SH, Park SK, Park E and Min YH. A prospective multicenter observational study of decitabine treatment in Korean patients with myelodysplastic syndrome. Haematologica. 2011; 96:1441-1447.

35. Platzbecker U, Schetelig J, Finke J, Trenschel R, Scott BL, Kobbe G, Schaefer-Eckart K, Bornhauser M, Itzykson R, Germing U, Beelen D, Ehninger G, Fenaux P, et al. Allogeneic hematopoietic cell transplantation in patients age 60-70 years with de novo high-risk myelodysplastic syndrome or secondary acute myelogenous leukemia: comparison with patients lacking donors who received azacitidine. Biol Blood Marrow Transplant. 2012; 18: 1415-1421.

36. Damaj G, Mohty M, Robin M, Michallet M, Chevallier P, Beguin Y, Nguyen S, Bories P, Blaise D, Maillard N, Rubio MT, Fegueux N, Cornillon J, et al. Upfront allogeneic stem cell transplantation after reducedintensity/nonmyeloablative conditioning for patients with myelodysplastic syndrome: a study by the Societe Francaise de Greffe de Moelle et de Therapie Cellulaire. Biol Blood Marrow Transplant. 2014; 20: 1349-1355.

37. Di Stasi A, Milton DR, Poon LM, Hamdi A, Rondon G, Chen J, Pingali SR, Konopleva M, Kongtim P, Alousi A, Qazilbash MH, Ahmed S, Bashir Q, et al. Similar transplantation outcomes for acute myeloid leukemia and myelodysplastic syndrome patients with haploidentical versus 10/10 human leukocyte antigen-matched unrelated and related donors. Biol Blood Marrow Transplant. 2014; 20:1975-1981.

38. Kantarjian HM, O'Brien S, Shan J, Aribi A, GarciaManero G, Jabbour E, Ravandi F, Cortes J, Davisson J and Issa JP. Update of the decitabine experience in higher risk myelodysplastic syndrome and analysis of prognostic factors associated with outcome. Cancer. 2007; 109: 265273.

39. Traina F, Visconte V, Elson P, Tabarroki A, Jankowska AM, Hasrouni E, Sugimoto Y, Szpurka H, Makishima H, O'Keefe CL, Sekeres MA, Advani AS, Kalaycio M, et al. Impact of molecular mutations on treatment response to 
DNMT inhibitors in myelodysplasia and related neoplasms. Leukemia. 2014; 28: 78-87.

40. Shaffer BC, Ahn KW, Hu ZH, Nishihori T, Malone AK, Valcarcel D, Grunwald MR, Bacher U, Hamilton B, Kharfan-Dabaja MA, Saad A, Cutler C, Warlick E et al. Scoring system prognostic of outcome in patients undergoing allogeneic hematopoietic cell transplantation for myelodysplastic syndrome. J Clin Oncol. 2016; 34: 1864-1871.

41. Bejar R, Stevenson KE, Caughey B, Lindsley RC, Mar BG, Stojanov P, Getz G, Steensma DP, Ritz J, Soiffer R, Antin JH, Alyea E, Armand P, Ho V, Koreth J, Neuberg D, et al. Somatic mutations predict poor outcome in patients with myelodysplastic syndrome after hematopoietic stem-cell transplantation. J Clin oncol. 2014; 32: 2691-2698.

42. Kim M, Yahng SA, Kwon A, Park J, Jeon YW, Yoon JH, Shin SH, Lee SE, Cho BS, Eom KS, Lee S, Min CK, Kim HJ, et al. Mutation in TET2 or TP53 predicts poor survival in patients with myelodysplastic syndrome receiving hypomethylating treatment or stem cell transplantation. Bone Marrow Transplant. 2015; 50: 1132-1134.

43. Itzykson R, Kosmider O, Cluzeau T, Mansat-De Mas V, Dreyfus F, Beyne-Rauzy O, Quesnel B, Vey N, Gelsi-Boyer V, Raynaud S, Preudhomme C, Ades L, Fenaux P, et al. Impact of TET2 mutations on response rate to azacitidine in myelodysplastic syndromes and low blast count acute myeloid leukemias. Leukemia. 2011; 25: 1147-1152.

44. Bejar R, Lord A, Stevenson K, Bar-Natan M, Perez-Ladaga A, Zaneveld J, Wang H, Caughey B, Stojanov P, Getz G, Garcia-Manero G, Kantarjian H, Chen R, et al. TET2 mutations predict response to hypomethylating agents in myelodysplastic syndrome patients. Blood. 2014; 124: 2705-2712.

45. Jung SH, Kim YJ, Yim SH, Kim HJ, Kwon YR, Hur EH, Goo BK, Choi YS, Lee SH, Chung YJ, Lee JH. Somatic mutations predict outcomes of hypomethylating therapy in patients with myelodysplastic syndrome. Oncotarget. 2016; 7:55264-55275. doi: 10.18632/oncotarget.10526.
46. Shin SH, Yahng SA, Yoon JH, Lee SE, Cho BS, Eom KS, Lee S, Min CK, Kim HJ, Cho SG, Kim DW, Lee JW, Min WS, et al. Survival benefits with transplantation in secondary AML evolving from myelodysplastic syndrome with hypomethylating treatment failure. Bone Marrow Transplant. 2013; 48: 678-683.

47. Cheson BD, Greenberg PL, Bennett JM, Lowenberg B, Wijermans PW, Nimer SD, Pinto A, Beran M, de Witte TM, Stone RM, Mittelman M, Sanz GF, Gore SD, et al. Clinical application and proposal for modification of the International Working Group (IWG) response criteria in myelodysplasia. Blood. 2006; 108: 419-425.

48. Prebet T, Gore SD, Esterni B, Gardin C, Itzykson R, Thepot S, Dreyfus F, Rauzy OB, Recher C, Ades L, Quesnel B, Beach CL, Fenaux P et al. Outcome of highrisk myelodysplastic syndrome after azacitidine treatment failure. J Clin Oncol. 2011; 29: 3322-3327.

49. Przepiorka D, Weisdorf D, Martin P, Klingemann HG, Beatty P, Hows J and Thomas ED. 1994 Consensus Conference on Acute GVHD Grading. Bone Marrow Transplant. 1995; 15: 825-828.

50. Filipovich AH, Weisdorf D, Pavletic S, Socie G, Wingard JR, Lee SJ, Martin P, Chien J, Przepiorka D, Couriel D, Cowen EW, Dinndorf P, Farrell A, et al. National Institutes of Health consensus development project on criteria for clinical trials in chronic graft-versus-host disease: I. Diagnosis and staging working group report. Biol Blood Marrow Transplant. 2005; 11: 945-956.

51. Sorror ML, Maris MB, Storb R, Baron F, Sandmaier BM, Maloney DG and Storer B. Hematopoietic cell transplantation (HCT)-specific comorbidity index: a new tool for risk assessment before allogeneic HCT. Blood. 2005; 106: 2912-2919. 